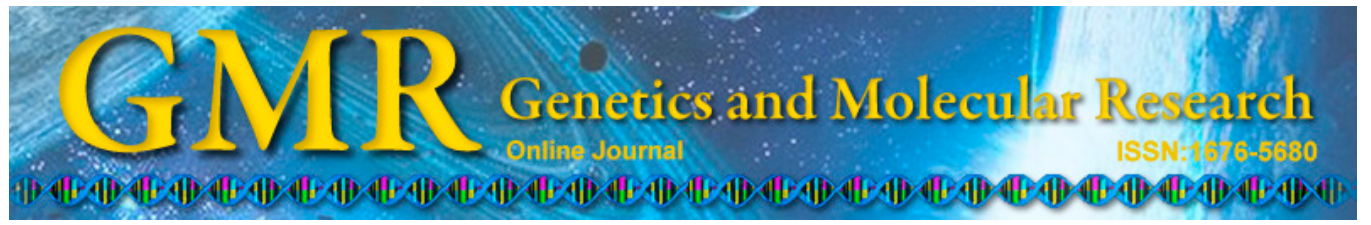

\title{
Heterosis for the improvement of yield in mungbean [Vigna radiata (L.) Wilczek]
}

\author{
P.A. Tantasawat ${ }^{1,2}$, P. Khajudparn ${ }^{1,2}$, T. Prajongjai ${ }^{1}$ and O. Poolsawat ${ }^{1}$ \\ ${ }^{1}$ School of Crop Production Technology, \\ Suranaree University of Technology, Nakhon Ratchasima, Thailand \\ ${ }^{2}$ Center of Excellence on Agricultural Biotechnology, \\ (AG-BIO/PERDO-CHE), Bangkok, Thailand \\ Corresponding author: P.A. Tantasawat \\ E-mail: piyada@sut.ac.th
}

Genet. Mol. Res. 14 (3): 10444-10451 (2015)

Received October 13, 2014

Accepted April 17, 2015

Published September 8, 2015

DOI http://dx.doi.org/10.4238/2015.September.8.5

\begin{abstract}
Heterotic effects of mungbean hybrids from 25 crosses between parents differing in 9 agronomic and physiological traits were evaluated for various selected traits and seed yield. Significant heteroses were observed in most selected traits, except for the number of seeds per plant. When the heterosis of seed yield was evaluated in these hybrids, significant heterosis was found in 9 crosses, which were selected based on the number of pods per plant, number of clusters per plant, pod length, number of seeds per pod, total dry matter, and root length density. These crosses may be exploited for mungbean yield improvement. Nine $\mathrm{F}_{8}$ lines from 2 of these 9 crosses (KPS 1 x V 2106 and SUT 1 x V 4785), a selection based on significant heterosis for seed yield and high seed yield of $F_{1}$ and $F_{2}$, which possessed a higher seed yield than their respective certified variety parents, were identified and these may be useful in future breeding programs.
\end{abstract}

Key words: Agronomic trait; Hybrid; Mungbean; Physiological trait; Plant breeding 


\section{INTRODUCTION}

Mungbean [Vigna radiata (L.) Wilczek] is one of the most important crops and a source of protein in South and South-East Asian countries, including Thailand, India, Indonesia, Myanmar, Pakistan, and Vietnam (Soehendi and Srinives, 2005; Rahim et al., 2008; Patel et al., 2009). It is well-adapted to low water and soil fertility, and has a short growth duration. In addition, it can be used in crop rotation practices (Somta and Srinives, 2007; Lavanya et al., 2008). Moreover, mungbean is rich in vitamins and protein, and its starch contains 32$35 \%$ amylase (Yu et al., 2011). In Thailand, mungbean is cultivated under both rain-fed and irrigated conditions. However, the present yield is not high enough to meet the demand of consumers and farmers because of its low yield potential, small seed size, and susceptibility to disease (Srivastava and Singh, 2013). Genetic studies, particularly those examining heterosis in mungbean, are crucial for selecting suitable parents for hybridization. Additionally, heterosis has important implications for both the $\mathrm{F}_{1}$ and $\mathrm{F}_{2}$ generations because it provides a basis for determining genetic diversity (Dethe and Patil, 2008). Although heteroses in mungbean for yield and its components have been reported previously in several studies (Ghafoor et al., 1990; Khattak et al., 2000; Xin et al., 2003; Soehendi and Srinives, 2005; Dethe and Patil, 2008; Patel et al., 2009; Zubair et al., 2010; Kumar and Prakash, 2011; Sorajjapinun et al., 2012; Srivastava and Singh, 2013), their magnitude was shown to vary according to parental genetic composition and must be determined for each individual cross. One of the major aims of the mungbean breeding program at the Suranaree University of Technology was to obtain maximum yield. To achieve this goal, knowledge of the magnitude of heterosis is required.

The objectives of this study were to estimate the extent of heterosis from 25 cross combinations of mungbean using data for seed yield and 9 major agronomic and physiological traits and to evaluate $\mathrm{F}_{8}$ lines from crosses with selection based on the information available.

\section{MATERIAL AND METHODS}

\section{Plant materials}

Four populations [female parent $\left(\mathrm{P}_{1}\right)$, male parent $\left(\mathrm{P}_{2}\right), \mathrm{F}_{1}$, and $\mathrm{F}_{2}$ ] of 25 cross combinations derived from hybridization between selected lines with desirable traits from the Asian Vegetable Research and Development Center (AVRDC) (V 1067, V 1414AG, V 1415AG, V 1946, V 2075, V 2106, V 3495, V 4451, V 4758, and V 4785; Khajudparn and Tantasawat, 2011) and elite lines (M 5-1, SUT 2, SUT 3, SUT 4, and SUT 5) or certified varieties (CN 36, CN 60, KPS 1, KPS 2, and SUT 1) were used. These mungbean crosses were chosen based on 9 agronomic and physiological traits consisting of 6 agronomic traits [number of pods/plant (CN 36 x V 2106, CN 36 x V 3495, CN 60 x V 4785, KPS 1 x V 4758, and SUT 5 x V 2106), number of clusters/plant (KPS 1 x V 2106), number of branches/plant (KPS 1 x V 3495), pod length (KPS 1 x V 1415AG, KPS 2 x V 1415AG, SUT 4 x V 1414AG, SUT 5 x V 1414AG, and SUT $5 \times$ V 1415AG), number of seeds/pod (CN 60 x V 4758, SUT 1 x V 4785, and SUT $3 \times$ V 4451), and number of seeds/plant (SUT 1 x V 4758 and SUT $2 \times$ V 2106)], as well as 3 physiological traits [total dry matter (CN 60 x V 1946, KPS 2 x V 1067, and SUT 4 x M 5-1), leaf area index (CN 36 x V 2075 and SUT 2 x V 2075), and root length density (CN 60 x V 1414AG, KPS 1 x V1415AG, and KPS 2 x V 1415AG)]. These crosses were grown in a 
randomized complete block design with 3 replications at the Suranaree University of Technology Farm, Nakhon Ratchasima, Thailand in August 2007. The $\mathrm{P}_{1}, \mathrm{P}_{2}$, and $\mathrm{F}_{1}$ populations were grown in single rows that were $5 \mathrm{~m}$ in length with spacing of $50 \mathrm{~cm}$ between rows and $20 \mathrm{~cm}$ between plants, and the $\mathrm{F}_{2}$ population was grown in 3 rows with the same length and spacing. The experimental plots were surrounded by non-experimental guard rows to avoid any possible conditional effects. Fertilizer (12-24-12 formula) and carbofuran $3 \mathrm{G}$ were applied at the rate of $187.5 \mathrm{~kg} / \mathrm{ha}$ and $10 \mathrm{~g} / \mathrm{hill}$, respectively. At 30 and 60 days after planting, the pesticide, monocrotophos [dimethyl $(E)$-1-methyl-2-(methylcarbamoyl) vinyl phosphate] was sprayed to save the crop from the infestation of insect pests. At maturity, data were recorded from 10 randomly chosen $\mathrm{P}_{1}, \mathrm{P}_{2}$, and $\mathrm{F}_{1}$ and 20 randomly chosen $\mathrm{F}_{2}$ plants in each replicate for seed yield (seed weight/plant) and 9 agronomic and physiological traits according to Khajudparn and Tantasawat (2011) and Khajudparn et al. (2012). Promising crosses with significant heteroses for seed yield and selected traits, as well as high seed yield in the $F_{1}$ and $F_{2}$, generations were selected. In each cross, 180-200 $\mathrm{F}_{2}$ progenies were self-pollinated and seeds were collected using the single seed descent method until the $\mathrm{F}_{6}$ generation. Selection began in the $\mathrm{F}_{6}$ generation (October 2009) when the best 40 of 180-200 progenies were selected based on the agronomic or physiological trait that the cross aimed to improve. At the $F_{7}$ generation (August 2010), seeds were planted in a single row that was $5 \mathrm{~m}$ in length with spacing of $50 \mathrm{~cm}$ between rows and $20 \mathrm{~cm}$ between plants, and the best 10 lines were selected. These selected lines and their respective certified variety parents were assessed for seed yield and 7 agronomic traits (number of branches/plant, number of clusters/plant, number of pods/plant, pod length, number of seeds/pod, number of seeds/plant, and 100 seed weight) using a randomized complete block design with 3 replications (a single row with the same length and spacing as above/replication) in November 2011.

\section{Significance testing of heterosis}

The data of the parents $\left(\mathrm{P}_{1}\right.$ and $\left.\mathrm{P}_{2}\right)$ and the $\mathrm{F}_{1}$ and $\mathrm{F}_{2}$ hybrids were statistically analyzed using SPSS version 14.0 (Levesque, 2006) (SPSS, Inc., Chicago, IL, USA). Heterosis was estimated by comparison to the parental mean (mid-parent heterosis) using the following formula:

Mid-parent heterosis $(\%)=\left[\left(\mathrm{F}_{1}-\mathrm{MP}\right) / \mathrm{MP}\right] \times 100$

Where $\mathrm{F}_{1}=$ mean of $\mathrm{F}_{1}$ hybrid for a trait

$\mathrm{MP}=$ mean of mid parents $\left[\left(\mathrm{P}_{1}+\mathrm{P}_{2}\right) / 2\right]$ for a trait

The significance of heterosis was determined using an independent $t$-test as described by Steel and Torrie (1980).

\section{RESULTS}

Heterosis and selected traits targeted for improvement in the $\mathrm{F}_{1}$ and $\mathrm{F}_{2}$ and their parents of each cross are presented in Table 1 . The differences among parents and the $\mathrm{F}_{1}$ were highly significant $(\mathrm{P}<0.01)$ for most of the traits, except for the number of seeds/plant. For the magnitude of heterosis, most traits observed from the 25 crosses showed significant and positive heteroses compared with the parental mean. These results suggest that the parents of most crosses showed genetic diversity for the trait selected and that heterosis occurred in their hybrids. 
Table 1. Agronomic and physiological traits of 4 populations $\left(\mathrm{P}_{1}, \mathrm{P}_{2}, \mathrm{~F}_{1}\right.$, and $\left.\mathrm{F}_{2}\right)$ and heteroses in 25 crosses of mungbean selected based on number of pods/plant, number of clusters/plant, number of branches/plant, pod length, number of seeds/pod, number of seeds/plant, total dry matter, leaf area index, and root length density.

\begin{tabular}{|c|c|c|c|c|c|}
\hline Crosses & $\mathrm{P}_{1}$ & $\mathrm{P}_{2}$ & $\mathrm{~F}_{1}$ & $\mathrm{~F}_{2}$ & Heterosis (\%) \\
\hline \multicolumn{6}{|l|}{ A. No. of pods/plant } \\
\hline $\mathrm{CN} 36 \times \mathrm{V} 2106$ & 21.1 & 42.4 & 38.0 & 27.4 & $17.0^{* *}$ \\
\hline CN 36 x V 3495 & 20.1 & 30.9 & 28.0 & 24.3 & $9.8^{* *}$ \\
\hline CN $60 \times$ V 4785 & 17.7 & 37.9 & 35.0 & 25.3 & $25.9^{* *}$ \\
\hline KPS 1 x V 4758 & 23.5 & 41.9 & 38.0 & 29.0 & $16.2 * *$ \\
\hline SUT 5 x V 2106 & 35.2 & 45.5 & 43.0 & 38.3 & $6.6^{* *}$ \\
\hline \multicolumn{6}{|l|}{ B. No. of clusters/plant } \\
\hline KPS 1 x V 2106 & 9.0 & 15.0 & 13.0 & 10.7 & $8.3^{* *}$ \\
\hline \multicolumn{6}{|l|}{ C. No. of branches/plant } \\
\hline KPS 1 x V 3495 & 9.0 & 14.2 & 12.9 & 10.4 & $11.2^{* *}$ \\
\hline \multicolumn{6}{|l|}{ D. Pod length (cm) } \\
\hline KPS $1 \times$ V 1415AG & 8.7 & 9.8 & 9.6 & 9.1 & $3.9^{* *}$ \\
\hline KPS 2 x V 1415AG & 9.0 & 10.5 & 10.1 & 9.4 & $3.5^{* *}$ \\
\hline SUT 4 x V 1414AG & 8.9 & 10.5 & 10.2 & 9.4 & $5.3^{* *}$ \\
\hline SUT 5 x V 1414AG & 7.2 & 10.6 & 9.4 & 8.6 & $5.7 * *$ \\
\hline SUT 5 x V 1415AG & 7.2 & 10.5 & 9.2 & 8.5 & $3.9^{* *}$ \\
\hline \multicolumn{6}{|l|}{ E. No. of seeds/pod } \\
\hline CN 60 x V 4758 & 7.6 & 11.6 & 10.2 & 8.8 & $6.3 * *$ \\
\hline SUT 1 x V 4785 & 9.1 & 11.7 & 10.8 & 10.0 & $3.9^{*}$ \\
\hline SUT 3 x V 4451 & 9.0 & 11.4 & 10.9 & 9.5 & $6.9^{* *}$ \\
\hline \multicolumn{6}{|l|}{ F. No. of seeds/plant } \\
\hline SUT 1 x V 4758 & 212.3 & 398.7 & 298.6 & 254.7 & $7.9^{\text {ns }}$ \\
\hline SUT 2 x V 2106 & 201.7 & 430.2 & 343.5 & 290.2 & $8.7^{\text {ns }}$ \\
\hline \multicolumn{6}{|l|}{ G. Total dry matter (g) } \\
\hline CN 60 x V 1946 & 11.4 & 31.7 & 24.2 & 19.3 & $12.8^{* *}$ \\
\hline KPS 2 x V 1067 & 18.4 & 29.2 & 26.9 & 21.7 & $13.0 * *$ \\
\hline SUT 4 x M 5-1 & 20.1 & 29.1 & 26.5 & 23.0 & $7.7 * *$ \\
\hline \multicolumn{6}{|l|}{ H. Leaf area index } \\
\hline CN $36 \times$ V 2075 & 3.1 & 4.2 & 3.9 & 3.5 & $6.9 *$ \\
\hline SUT $2 \times$ V 2075 & 2.4 & 4.1 & 3.7 & 2.9 & $13.9^{* *}$ \\
\hline \multicolumn{6}{|c|}{ I. Root length density $\left(\mathrm{cm} / \mathrm{cm}^{3}\right.$ soil volume) } \\
\hline CN $60 \times$ V $1414 A G$ & 0.5 & 0.9 & 0.8 & - & $19.4 * *$ \\
\hline KPS $1 \times$ V 1415AG & 0.6 & 0.8 & 0.8 & - & $13.5^{*}$ \\
\hline KPS 2 x V1415AG & 0.7 & 0.8 & 0.9 & - & $16.3^{* *}$ \\
\hline
\end{tabular}

$*$ and $* *$ Significant heterotic effects at 5 and $1 \%$ probability levels, respectively; ns $=$ non-significant.

The results from the 5 crosses selected based on the number of pods/plant revealed that heterosis for this trait ranged from $6.6-25.9 \%$. The maximum heterosis $(25.9 \%)$ was observed in the hybrid of the CN $60 \times$ V 4785 cross (Table 1A). For the number of clusters/plant, only 1 cross (KPS 1 x V 2106) was selected. The heterosis for this cross was $8.3 \%$ (Table 1B). Similarly, the single cross (KPS 1 x V 3495), which was selected based on the number of branches/plant, showed $11.2 \%$ heterosis (Table 1C). For the 5 crosses selected to increase pod length, all crosses (KPS 1 x V 1415AG, KPS 2 x V 1415AG, SUT 4 x V 1414AG, SUT 5 $x$ V 1414AG, and SUT 5 x V 1415AG) produced very low heterosis (3.5-5.7\%). Among these crosses, $\mathrm{F}_{1}$ of the SUT 5 x V 1414AG cross showed the highest heterosis (5.7\%) (Table 1D). For the number of seeds/pod, 3 crosses (CN $60 \times$ V 4758, SUT 1 x V4785, and SUT $3 \times$ V 4451) showed heteroses ranging from 3.9-6.9\%. The highest heterosis $(6.9 \%)$ was observed in the SUT $3 \times$ V 4451 cross (Table 1E). Heteroses of crosses (SUT 1 x V 4758 and SUT $2 \times$ V 2106) selected based on the number of seeds/plant ranged from $7.9-8.7 \%$, but the values were 
not significant $(\mathrm{P}>0.05)$ (Table 1F). For crosses selected based on total dry matter, heteroses ranged from 7.7-13.0\%. The maximum average heteroses were observed in 2 crosses (CN 60 $x$ V 1946 and KPS 2 x V1067) from the 3 crosses (Table 1G). For the 2 crosses selected based on leaf area index (CN 36 x V 2075 and SUT 2 x V 2075), heteroses ranged from 6.9-13.9\%. The cross SUT 2 x V 2075 showed better heterosis than CN 36 x V 2075 (Table 1H). In the case of root length density, all 3 crosses showed positive average heteroses, with values ranging from 13.5-19.4\%. The maximum average heterotic effect (19.4\%) was expressed by the $\mathrm{F}_{1}$ of the CN 60 x V 1414AG cross (Table 1I).

Heterotic effects were significant for number of pods/plant, number of clusters/plant, number of branches/plant, pod length, number of seeds/pod, total dry matter, leaf area index, and root length density. In traits with more than 1 cross, the best crosses identified for each trait were CN 60 x V 4785 (number of pods/plant), SUT 5x V 1414AG (pod length), SUT 3 x V 4451 (number of seeds/pod), KPS 2 x V 1067 (total dry matter), SUT 2 x V 2075 (leaf area index), and CN 60 x V 1414AG (root length density) (Table 1).

To develop high-yielding mungbean varieties by improving the above traits, heterosis for seed yield (seed weight/plant) of the 25 crosses was evaluated. The results are presented in Table 2. We found that 9 crosses, including CN 36 x V 2106, CN $60 \times$ V 1414AG, CN $60 \times$ V 1946, CN 60 x V 4758, CN 60 x V 4785, SUT 1 x V 4785, SUT 3 x V 4451, KPS 1 x V 2106, and KPS $2 \times$ V 1415AG, produced significant and positive heterotic effects for seed yield (Table 2A, B, D, E, G, and I). Two of these 9 crosses exhibited maximum average $\mathrm{F}_{1}$ seed yield [KPS 1 x V 2106 (selected based on number of clusters/plant) and SUT 1 x V 4785 (selected based on number of seeds/pod)] (13.5 and $14.2 \mathrm{~g}$, respectively). Moreover, they showed a high average of $\mathrm{F}_{2}$ seed yield (12.5 and $13.8 \mathrm{~g}$, respectively) (Table 2B and E). In contrast, no significant heterosis for yield was observed in 16 crosses, implying that a diversified germplasm is needed in breeding programs to improve the yield of these crosses (Table 2).

For yield improvement, 2 crosses (KPS 1 x V 2106 and SUT 1 x V 4785) were chosen based on the significant heterosis for seed yield and high seed yield observed for the $F_{1}$ and $F_{2}$. The single seed descent method was used from the $\mathrm{F}_{2}$ to the $\mathrm{F}_{6}$ generation with 180-200 progenies/cross in each generation. The best 40 lines with high values for the selected trait were selected at the $\mathrm{F}_{6}$ generation, and the 10 best lines were selected at the $\mathrm{F}_{7}$ generation. These selected lines were evaluated for seed yield and 7 agronomic traits at the $\mathrm{F}_{8}$ generation. We found that 2 of 10 lines from the KPS 1 x V 2106 cross and 7 of 10 lines from the SUT 1 x V 4785 cross had higher seed yield than their respective certified variety parents. Table 3 shows the seed yield and agronomic traits of these 9 potential lines.

\section{DISCUSSION}

Currently, heterosis in mungbean has generated an interest among plant breeders for the development of hybrid mungbean varieties as well as selection of suitable parents. For example, Patel et al. (2009) found significant standard heterosis for component traits such as days to $50 \%$ flowering and number of pods/plant in the cross of PDM-87 x K 851 and PDM143 x GM 3. Zubair et al. (2010) observed a high level of heterosis for seed yield/plant, plant height, and number of pods/plant. Similar results for seed yield/plant in mungbean have been reported by Srivastava and Singh (2013). In addition, Kumar and Prakash (2011) reported heterosis for total chlorophyll and seed protein in mungbean. They also found crosses with the highest relative heterosis and heterobeltiosis for both traits. 
Table 2. Seed yield (seed weight/plant) of 4 populations $\left(\mathrm{P}_{1}, \mathrm{P}_{2}, \mathrm{~F}_{1}\right.$, and $\left.\mathrm{F}_{2}\right)$ and heteroses in 25 crosses selected based on number of pods/plant, number of clusters/plant, number of branches/plant, pod length, number of seeds/pod, number of seeds/plant, total dry matter, leaf area index, and root length density.

\begin{tabular}{|c|c|c|c|c|c|}
\hline \multirow[t]{2}{*}{ Crosses } & \multicolumn{4}{|c|}{ Seed weight/plant (g) } & \multirow[t]{2}{*}{ Heterosis (\%) } \\
\hline & $P_{1}$ & $\mathrm{P}_{2}$ & $\mathrm{~F}_{1}$ & $\mathrm{~F}_{2}$ & \\
\hline \multicolumn{6}{|l|}{ A. No. of pods/plant } \\
\hline CN 36 x V 2106 & 9.1 & 14.5 & 12.9 & 11.2 & $9.3^{* *}$ \\
\hline CN 36 x V 3495 & 9.2 & 11.8 & 10.9 & 11.2 & $3.8^{\mathrm{ns}}$ \\
\hline CN $60 \times$ V 4785 & 6.8 & 15.8 & 12.4 & 11.5 & $9.7 * *$ \\
\hline KPS 1 x V 4758 & 11.9 & 15.6 & 13.5 & 12.7 & $-1.8^{\mathrm{ns}}$ \\
\hline SUT 5 x V 2106 & 12.5 & 14.6 & 13.8 & 13.5 & $1.9^{\mathrm{ns}}$ \\
\hline \multicolumn{6}{|l|}{ B. No. of clusters/plant } \\
\hline KPS 1 x V 2106 & 11.2 & 14.5 & 13.5 & 12.5 & $5.1^{*}$ \\
\hline \multicolumn{6}{|l|}{ C. No. of branches/plant } \\
\hline KPS 1 x V 3495 & 11.0 & 13.5 & 12.9 & 12.5 & $5.3^{\text {ns }}$ \\
\hline \multicolumn{6}{|l|}{ D. Pod length } \\
\hline KPS 1 x V 1415AG & 11.7 & 7.9 & 10.2 & 9.8 & $4.1^{\text {ns }}$ \\
\hline KPS 2 x V 1415AG & 14.0 & 8.0 & 12.4 & 12.0 & $12.7^{* *}$ \\
\hline SUT 4 x V 1414AG & 11.6 & 9.2 & 10.8 & 10.2 & $3.9^{\text {ns }}$ \\
\hline SUT 5 x V 1414AG & 13.6 & 9.4 & 12.4 & 11.8 & $7.8^{\mathrm{ns}}$ \\
\hline SUT 5 x V 1415AG & 13.8 & 8.1 & 11.5 & 11.1 & $5.0^{\text {ns }}$ \\
\hline \multicolumn{6}{|l|}{ E. No. of seeds/pod } \\
\hline CN 60 x V 4758 & 6.8 & 15.9 & 12.6 & 10.8 & $11.0^{* *}$ \\
\hline SUT 1 x V 4785 & 10.7 & 15.7 & 14.2 & 13.8 & $7.4^{* *}$ \\
\hline SUT 3 x V 4451 & 10.4 & 12.8 & 11.8 & 11.2 & $1.7^{* *}$ \\
\hline \multicolumn{6}{|l|}{ F. No. of seeds/plant } \\
\hline SUT 1 x V 4758 & 14.5 & 16.3 & 16.1 & 14.6 & $4.7^{\mathrm{ns}}$ \\
\hline SUT 2 x V 2106 & 16.8 & 21.0 & 21.8 & 18.0 & $15.5^{\mathrm{ns}}$ \\
\hline \multicolumn{6}{|l|}{ G.Total dry matter } \\
\hline CN 60 x V 1946 & 7.0 & 13.9 & 12.4 & 12.0 & $18.7^{* *}$ \\
\hline KPS 2 x V 1067 & 14.1 & 11.0 & 13.1 & 12.5 & $4.4^{\mathrm{ns}}$ \\
\hline SUT 4 x M 5-1 & 10.5 & 11.7 & 11.2 & 10.4 & $0.9^{\text {ns }}$ \\
\hline \multicolumn{6}{|l|}{ H. Leaf area index } \\
\hline CN 36 x V 2075 & 9.4 & 12.5 & 10.9 & 10.5 & $-0.3^{\text {ns }}$ \\
\hline SUT 2 x V 2075 & 9.4 & 13.8 & 11.9 & 11.2 & $2.7^{\mathrm{ns}}$ \\
\hline \multicolumn{6}{|l|}{ I. Root length density } \\
\hline $\mathrm{CN} 60 \times \mathrm{V} 1414 \mathrm{AG}$ & 7.6 & 10.3 & 9.8 & - & $9.5^{*}$ \\
\hline KPS $1 \times$ V $1415 A G$ & 9.8 & 8.1 & 9.2 & - & $3.7^{\mathrm{ns}}$ \\
\hline KPS 2 x V1415AG & 13.7 & 7.8 & 10.7 & - & $-0.5^{\text {ns }}$ \\
\hline
\end{tabular}

* and ${ }^{* *}$ Significant heterotic effects at 5 and $1 \%$ probability levels, respectively; ns $=$ non-significant.

Table 3. Agronomic traits and seed yield (seed weight/plant) of 9 potential lines of KPS 1 x V 2106 and SUT $1 \mathrm{x} \mathrm{V} 4785$ crossesat $\mathrm{F}_{8}$ generation.

\begin{tabular}{|c|c|c|c|c|c|c|c|c|c|}
\hline Crosses/varieties & Lines & $\begin{array}{l}\text { Seed weight/ } \\
\text { plant }(\mathrm{g})\end{array}$ & $\begin{array}{l}\text { No. of branches/ } \\
\text { plant }\end{array}$ & $\begin{array}{l}\text { No. of clusters/ } \\
\text { plant }\end{array}$ & $\begin{array}{l}\text { No. of pods/ } \\
\text { plant }\end{array}$ & $\begin{array}{l}\text { Pod length } \\
\text { (cm) }\end{array}$ & $\begin{array}{c}\text { No. of } \\
\text { seeds/pod }\end{array}$ & $\begin{array}{c}\text { No. of } \\
\text { seeds/plant }\end{array}$ & $\begin{array}{c}100 \text { seed } \\
\text { weight }(\mathrm{g})\end{array}$ \\
\hline KPS $1 \times$ V 2106 & SUT49-43 & 13.14 & 7.80 & 33.53 & 31.70 & 8.57 & 11.01 & 230.90 & 6.09 \\
\hline (No. of clusters/plant) & SUT49-139 & 14.60 & 6.67 & 26.53 & 37.07 & 7.90 & 10.50 & 254.49 & 6.13 \\
\hline SUT 1 x V 4785 & SUT49-27 & 16.32 & 6.90 & 26.67 & 49.67 & 7.20 & 11.27 & 405.33 & 4.20 \\
\hline \multirow[t]{6}{*}{ (No. of seeds/pod) } & SUT49-28 & 14.26 & 7.43 & 27.20 & 33.73 & 7.43 & 11.19 & 293.33 & 4.87 \\
\hline & SUT49-33 & 14.97 & 6.80 & 25.57 & 36.57 & 7.63 & 11.96 & 310.90 & 4.91 \\
\hline & SUT49-62 & 15.47 & 6.57 & 21.60 & 36.80 & 7.90 & 11.26 & 299.37 & 5.53 \\
\hline & SUT49-176 & 14.37 & 6.27 & 25.30 & 43.23 & 7.53 & 11.83 & 355.63 & 4.22 \\
\hline & SUT49-178 & 15.05 & 6.67 & 23.37 & 45.50 & 7.57 & 11.48 & 370.00 & 4.18 \\
\hline & SUT49-179 & 16.22 & 6.60 & 23.73 & 43.63 & 7.43 & 11.45 & 356.53 & 4.73 \\
\hline KPS 1 & & 12.02 & 6.99 & 24.54 & 28.04 & 8.49 & 10.56 & 196.08 & 6.64 \\
\hline SUT 1 & & 13.93 & 7.17 & 23.20 & 32.43 & 8.58 & 9.89 & 207.87 & 6.96 \\
\hline
\end{tabular}


We previously reported the relationships and variability between agronomic and physiological characters in mungbean and found that the number of clusters/plant, number of seeds/pod, total dry matter, and number of pods/plant were suitable selection criteria for yield improvement. Several potential lines possessing high values of desirable traits related to yield were also identified (Khajudparn and Tantasawat, 2011). In this experiment, these potential lines and certified varieties/elite lines were crossed for heterosis assessment. Our results confirmed that the magnitude of heterosis was dependent upon the genotypes of the parents. Positive and significant heteroses were observed in 23 of 25 crosses for the selected traits, but only 9 crosses (CN 36 x V 2106, CN 60 x V 1414AG, CN 60 x V 4785, CN 60 x V 1946, CN 60 x V 4758, SUT 1 x V 4785, SUT 3 x V 4451, KPS 1 x V 2106, and KPS 2 x V 1415AG) produced positive and significant heterotic effects for seed yield. These 9 crosses can be exploited to develop high-yielding mungbean varieties in future studies. Selection in these 9 crosses was based on the number of pods/plant, number of clusters/plant, pod length, number of seeds/pod, total dry matter, or root length density, which was expected because the number of clusters/plant, number of seeds/pod, total dry matter, number of pods/plant, and root length density were found to be significantly correlated with seed yield in mungbean (Khajudparn and Tantasawat, 2011; Khajudparn et al., 2012). Further evaluation of 2 of these crosses from the $\mathrm{F}_{8}$ generation showed that 9 lines gave higher seed yield than their respective certified variety parents. These lines also possessed higher values for the traits that their selection was based on, suggesting that selection based on traits with a significant correlation to yield in a cross showing significant heterosis for yield is efficient for yield improvement in mungbean. Of particular interest are the lines SUT49-139 and SUT49-62, which showed high seed yield as well as relatively large seed size. Our recent results indicated that the lines SUT49-43 and SUT49-179 were resistant to powdery mildew (Sphaerotheca phaseoli) and line SUT49-43 also provided resistance to leaf spot (Cercospora canescens Ellis \& Martin) (Tantasawat and Poolsawat, unpublished results), making these lines very useful for future breeding programs.

\section{ACKNOWLEDGMENTS}

Research partially supported by the Higher Education Research Promotion and National Research University Project of Thailand, Office of the Higher Education Commission, the Center of Excellence on Agricultural Biotechnology, Science and Technology Postgraduate Education and Research Development Office, Office of the Higher Education Commission, Ministry of Education (AG-BIO/PERDO-CHE), and grants from Suranaree University of Technology, Thailand. The authors also thank Mr. Peter Charles Bint for editing the manuscript, and Prof. Paisan Laosuwan for useful advice.

\section{REFERENCES}

Dethe AM and Patil JV (2008). Heterosis studies in mungbean [Vigna radiata (L.) Wilczek]. Legume Res. 31: 36-39.

Ghafoor A, Zubair M, Bakhsh A and Bashir M (1990). Heterosis among seven parents and their crosses in mungbean. Pakistan J. Agric. Res. 11: 169-173.

Khajudparn P and Tantasawat P (2011). Relationships and variability of agronomic and physiological characters in mungbean. Afr. J. Biotechnol. 10: 9992-10000.

Khajudparn P, Boonjung H, Laosuwan P and Tantasawat P (2012). Association between root length density and seed yield in mungbean [Vigna radiata (L.) Wilczek]. Environ. Res. J. 6: 277-286.

Khattak GSS, Haq MA, Ashraf M and Tahir GR (2000). Heterosis for some morphological traits in mungbean [Vigna 
radiata (L.) Wilczek]. Kasetsart J. (Nat. Sci.) 34: 439-442.

Kumar BS and Prakash M (2011). Heterosis for biometric and biochemical components in mungbean [Vigna radiata (L.) Wilczek]. Karnataka J. Agric. Sci. 24: 523-524.

Lavanya GR, Srivastava J and Ranade SA (2008). Molecular assessment of genetic diversity in mung bean germplasm. J. Genet. 87: 65-74.

Levesque R (2006). SPSS programming and data management. 3rd edn. Somers, New York.

Patel MB, Patel BN, Savaliya JJ and Tikka SBS (2009). Heterosis and genetic architecture of yield, yield contributing traits and yellow mosaic virus in mungbean [Vigna radiata (L.) Wilczek]. Legume Res. 32: 260-264.

Rahim MA, Mia AA, Mahmud F and Afrin KS (2008). Multivariate analysis in some mungbean [Vigna radiata (L.) Wilczek] accessions on the basis of agronomic traits. Am.-Euras. J. Sci. Res. 3: 217-221.

Soehendi R and Srinives P (2005). Significance of heterosis and heterobeltiosis in an $\mathrm{F}_{1}$ hybrid of mungbean [Vigna radiata (L.) Wilczek] for hybrid seed production. SABRAO J. Breed. Gen. 37: 97-105.

Somta P and Srinives P (2007). Genome research in mungbean [Vigna radiata (L.) Wilczek] and blackgram [V. mungo (L.) Hepper]. ScienceAsia 33S: 69-74.

Sorajjapinun W, Chankaew S and Srinives P (2012). Comparison of hybrid vigor based on parental distance in SSR markers and agronomic traits in mungbean [Vigna radiata (L.) Wilczek]. Songklanakarin J. Sci. Technol. 34: 143-151.

Srivastava RL and Singh G (2013). Heterosis for yield and its contributing characters in mungbean [Vigna radiata (L.) Wilczek]. Indian J. Sci. Res. 4: 131-134.

Steel RGD and Torrie JH (1980). Principles and proceedings of statistics: a biometrical approach. 2nd edn. New York.

Xin C, Sorajjapinun W, Reiwthongchum S and Srinives P (2003). Identification of parental mungbean lines for production of hybrid varieties. CMU J. 2: 97-105.

Yu SC, Lin PC and Lin J (2011). Effects of extrusion processing condition on the physic-chemical properties of mungbean extrudates. Proceedings of the 12th Asian Food Conference 2011, Bangkok, Thailand, 524-526.

Zubair M, Ajmal SU and Ali S (2010). Heterosis for yield related attributes in mungbean [Vigna radiata (L.) Wilczek]. Pak. J. Bot. 42: 3209-3214. 